\title{
RELAÇÕES SOLO, SUPERFÍCIE GEOMÓRFICA E SUBSTRATO GEOLÓGICO NA MICROBACIA DO RIBEIRÃO MARINS (PIRACICABA - SP) ${ }^{1}$
}

\author{
Edson Roberto Teramoto ${ }^{2 *}$; Igo Fernando Lepsch³ Pablo Vidal-Torrado ${ }^{4}$ \\ ${ }_{3}^{2}$ Depto. de Produção Vegetal - USP/ESALQ. \\ ${ }^{3}$ Depto. de Ciência do Solo - Faculdade de Agronomia / Universidade Federal de Uberlândia. \\ ${ }^{4}$ Depto. de Solos e Nutrição de Plantas - USP/ESALQ, C.P. 9 - CEP: 13418-900, Piracicaba - SP. \\ *Autor correspondente <erteramo@carpa.ciagri.usp.br>
}

\begin{abstract}
RESUMO: O estudo das inter-relações entre aspectos pedológicos, geológicos e geomorfológicos de uma área são importantes para a compreensão da distribuição das unidades de mapeamento de solos na paisagem, constuituindo importante ferramenta para mapeamento de solos. Com o objetivo de estabelecer essas relações, efetuou-se um mapeamento detalhado dos depósitos geológicos superficiais, das superfícies geomórficas e das unidades de solos de uma área na microbacia do ribeirão Marins em Piracicaba, SP. Tais relações foram obtidas através de um sistema geográfico de informações e de um índice de homogeneidade para avaliar quantitativamente as inter-relações de cada tema estudado. A estratigrafia da área está representada por siltitos e folhelhos da formação Corumbataí, arenitos da formação Pirambóia, uma cobertura neo-cenozóica de textura média e por sedimentos holocênicos coluviais e aluviais. Foram identificadas cinco superfícies geomórficas e foram estabelecidas dez unidades de mapeamento em cinco classes, LATOSSOLO, ALISSOLO, ARGISSOLO, CAMBISSOLO e NEOSSOLO. o LATOSSOLO VERMELHO-AMARELO está relacionado à cobertura neocenozóica e à superfície I, mais alta. O ALISSOLO e os ARGISSOLOS VERMELHO-AMARELOS de textura arenosa/média relacionam-se aos arenitos da formação Pirambóia e às superfícies II e III em áreas com declive suave, posicionadas abaixo da I. Os NEOSSOLOS LITÓLICOS argilosos estão associados aos siltitos da formação Corumbataí, ocorrendo nas superfícies IV e V, mais recentes, inferiores e em áreas muito inclinadas. Os CAMBISSOLOS HÁPLICOS de textura variada relacionam-se aos alúvios-colúvios da base. Quanto mais velha e estável for a superfície geomórfica mais homogênea ela é em relação aos solos que nela ocorrem. A evolução pedogenética é maior na medida em que em que aumenta a idade da superfície. A variabilidade dos atributos químicos e físicos dos solos na camada de 60-80cm é influenciada principalmente pela natureza química e física do substrato geológico, enquanto que os atributos morfológicos são determinados principalmente pelo relevo. Estas relações se repetem na paisagem da microbacia com características de solo, relevo e litologia semelhantes, permitindo sua extrapolação para outras áreas, contribuindo para futuros levantamentos detalhados de solos que possam vir a ser realizados na região.
\end{abstract}

Palavras-chave: relações solo geomorfologia, estratigrafia, pedogênese

\section{SOIL, GEOLOGICAL SUBSTRATE AND GEOMORPHIC SURFACE RELATIONSHIPS FOR THE MARINS RIVER BASIN (PIRACICABA, SP, BRAZIL)}

\begin{abstract}
The relationships between soil, geology and geomorphic surface were studied in the Marins basin of Piracicaba, S.P., Brazil. Soils, parent material, geology and geomorphic surfaces were mapped. Two transects were studied to verify the lateral variation of the soils. Geology derives from Neo-Cenozoic superficial deposits of a loamy sand texture, sandstone belonging to the Piramboia Formation of the São Bento group, with siltstones and shales belonging to the Corumbatai Formation of the Passa Dois group, and colluvial and alluvial sediments. Five geomorphic surfaces were identified. The relationships between soil, parent material, geology and geomorphic surfaces were performed cross-referencing the different maps. These relations were analyzed by comparision to an "uniformity index", specialy developed to verify the inter-relation uniformity. Ten soil units were identified (Oxisol, Ultisol and Inceptisol orders). The Oxisol is related to the neocenozoic cover and surface I, were the relief is almost flat. The Ultisol, with a predominance of a sandy loam texture, is related to the Pirambóia formation sandstone and to surfaces II and III, with gentle slopes. The Incepstisol, with a clayey texture, are associated to the Corumbatai formation siltstone and silex, with IV and V surfaces (ondulating relief). The Incepitsols of varied textures are related to alluvium and colluvium deposits. The relation that exists between the soils and the geomorphic surfaces is represented by the tendency that, the older and more stable the surface is, more homogeous it is in relation to the soils formed on it. The relation established in this area of study, is repeated in the landscape in other locations of the basin with soil, relief and lithological characteristics similar to the ones of the studied area. This shows that the relations established in this area can be extrapolated to other, contibuting in this way to future soils surveys that could be perfomed in this basin.
\end{abstract}

Key words: soil geomorphology relantionships, stratigraph, pedogenesis

${ }^{1}$ Parte da Dissertação de Mestrado do primeiro autor apresentada à USP/ESALQ - Piracicaba, SP.

Scientia Agricola, v.58, n.2, p.361-371, abr./jun. 2001 


\section{INTRODUÇÃO}

Os estudos das relações entre solos, geologia e superfícies geomórficas são importantes para a compreensão da ocorrência dos solos na paisagem, permitindo a predição dessa distribuição (Daniels et al., 1971), e por isso constituem-se em importantes ferramentas para atividades de mapeamento de solos e de planejamento de uso do solo. Tais estudos tiveram grande impulso principalmente com os trabalhos de Ruhe (1969) e Daniels et al. (1971) cujos conceitos são utilizados neste trabalho.

Autores como Azolin et al. (1975); Rodrigues \& Klamt (1978); Lepsch et al. (1977); Perez Filho (1980); Lobo (1984); Uberti \& Klamt (1984); Berg et al. (1987); Vidal-Torrado (1994); Coelho, et al. (1994), entre outros, dedicaram-se a estes estudos para compreender a dinâmica e a distribuição dos solos na paisagem.

Para estudar as interações entre solos, substratos geológicos e superfícies geomórficas, escolheu-se uma área numa microbacia no município de Piracicaba, SP, compreendendo uma cobertura cenozóica, arenito e siltitos. Esta área constitui um segmento representativo desta microbacia e de boa parte do município pois é comum a ocorrência, na região, das seqüências litoestratigráficas arenito-siltito, referentes às Formações Pirambóia e Corumbataí, respectivamente.

\section{MATERIAL E MÉTODOS}

A área situa-se no município de Piracicaba-SP, entre as coordenadas $22^{\circ} 47^{\prime}$ e $22^{\circ} 49^{\prime}$ de latitude sul e $48^{\circ} 47^{\prime}$ e $48^{\circ} 49^{\prime}$ de longitude oeste, na microbacia do ribeirão Marins, constituindo uma faixa de 465,7 ha, desde o divisor de águas até a margem direita do citado ribeirão (Figura 1).

O clima da região é classificado no sistema Koppen como Cwa, isto é, mesotérmico úmido subtropical de inverno seco (Brasil, 1960). O regime térmico dos solos é hipertérmico segundo Oliveira el al. (1976). Para solos mais espessos o regime de umidade é údico, mas para os rasos é mais provável que seja ústico. Segundo IPT (1981a), a litologia é representada por rochas sedimentares dos grupos São Bento e Passa Dois, representados pelas formações Pirambóia, caracterizados por arenitos finos a médios, siltosos e argilosos e, formação Corumbataí, caracterizados por siltitos, arenitos finos a médios, sílticos argilosos e por depósitos marinhos, predominando siltitos, arenitos finos em parte concrecionados por calcário e sílex. De acordo com IPT (1981b), a área de estudo está localizada na Depressão Periférica Paulista, na zona do Médio Tietê. Apresenta relevo plano a suavemente ondulado no topo; e em direção ao ribeirão Marins torna-se ondulado. No levantamento semi-detalhado de solos do Estado de São Paulo, quadrícula de Piracicaba, Oliveira \& Prado (1989) observaram, na antiga classificação de solos, a presença

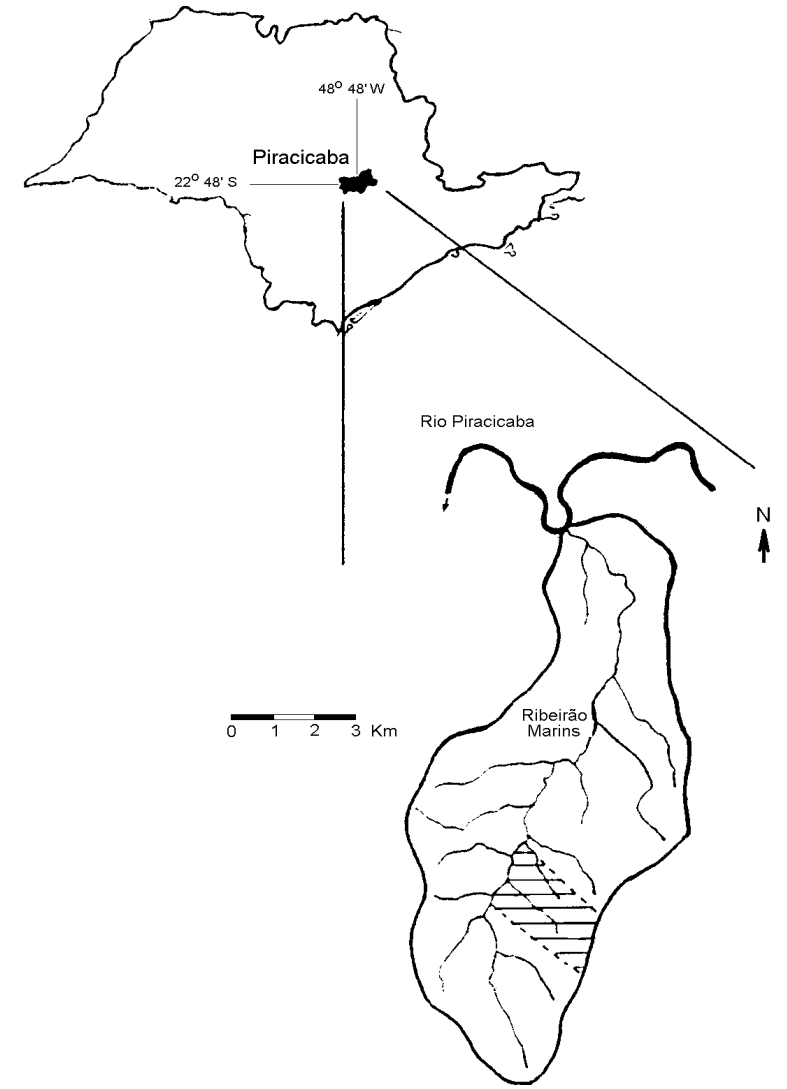

Figura 1 - Localização da área em relação à microbacia do ribeirão Marins.

de latossolo vermelho-amarelo textura média, podzólico vermelho-amarelo e solos litólicos indiscriminados relacionados com o grupo Passa Dois. A identificação dos substratos geológicos foi realizada através de tradagens e observações em cortes de estradas. A área estudada está ocupada pela cultura da cana-de-açúcar há mais de 8 anos.

Locaram-se duas transeções, uma no topo e a outra encosta abaixo, até o ribeirão Marins. Em ambas coletaram-se amostras de terra em pontos a intervalos de $50 \mathrm{~m}$, nas camadas de $0-20 \mathrm{~cm}$ e $60-80 \mathrm{~cm}$ (Figura 4).

Nas amostras de solo (TFSA) determinaram-se o pH em água e em $\mathrm{KCl} 1 \mathrm{~mol} \mathrm{~L}^{-1}$ e os teores de cálcio, magnésio, potássio, hidrogênio e o alumínio trocáveis e o carbono orgânico, segundo Raij et al. (1987). Para a análise granulométrica (argila, silte e cinco frações de areia), usou-se o método do densímetro, (Camargo et al. 1986). A separação das superfícies geomórficas seguiu os critérios de Ruhe (1969) e Daniels et al. (1971). Segundo esses autores uma superfície geomórfica é uma porção da superfície terrestre especificamente definida no tempo e no espaço. O mapeamento de solos foi realizado em nível detalhado.

As interações entre as unidades de mapeamento de solos, litologia e superfícies geomórficas foram estabelecidas cruzando-se as informações dos mapas, utilizando-se o programa GMAP (Sparovek et al. 1993). 
A interpretação dessas interrelações baseou-se no conceito de homogeneidade das superfícies geomórficas em relação às unidades de mapeamento de solos e litologia existentes em cada uma delas, e da mesma forma para litologia em relação às unidades de mapeamento de solos. Para contornar a aparente subjetividade dos trabalhos de relações solo-paisagem, foi desenvolvido um índice quantitativo, denominado de "índice de homogeneidade" (IH). Este índice equivale a uma média ponderada das ocorrências dos fatores estudados sendo que o peso é o próprio valor da ocorrência destes fatores. Matematicamente foi definido como sendo a somatória dos quadrados das porcentagens das ocorrências dos fatores considerados, expresso em termos percentuais. A equação é descrita a seguir:

$$
\mathrm{l} \%=(\mathrm{F})^{2} / 100
$$

onde: $1 \%$ = índice de homogeneidade litológico ou pedológico, em porcentagem; $F=$ porcentagem de ocorrência do fator.

O valor da ocorrência $(F)$ foi elevado ao quadrado por que dessa forma o peso de cada fator é o valor de sua própria ocorrência, obedecendo assim o comportamento de uma função quadrática. Nota-se que quanto menor o valor de $\mathrm{F}$, menor será o incremento após ser elevado ao quadrado e vice-versa. No caso de números decimais menores que 1 (um), não haverá incremento, ou seja, o valor de $\mathrm{F}$ após ser elevado ao quadrado será menor que o original. Segundo Murray (1985) números índices podem ser utilizados para mostrar as variações geográficas de uma variável, ou de um grupo delas, correlacionadas no tempo, à localização geográfica e a muitas outras características.

\section{RESULTADOS E DISCUSSÃO}

\section{Litologia}

Tradagens profundas com pelo menos $7 \mathrm{~m}$ evidenciaram que além das formações geológicas mostradas nos mapas geológicos (IPT, 1981a) a estratigrafia da área está representada por uma formação superficial neo-cenozóica, (Figura 2).

A área estudada é dominada por siltitos e folhelhos da formação Corumbataí, que ocupa mais da metade do seu total, seguido pela formação Pirambóia e pela cobertura Neocenozóica. As áreas de cada formação estão indicadas na TABELA 1. A cobertura neo-cenozóica, possui textura média, alta permeabilidade, cor com matiz variando de 5 YR e 2,5 YR. Esta cobertura pode estar relacionada com a formação Rio Claro (Bjornberg \& Landim, 1966, Oka-Fiori \& Christofoletti, 1983).

$\mathrm{Na}$ área de estudo a cobertura neocenozóica assenta-se sobre rochas da formação Pirambóia. Isso sugere que sua origem é deposicional e que este depósito é mais recente que as duas formações geológicas subjacentes reforçando a idéia de seu aloctonismo (Penteado, 1976; Vidal-Torrado, 1994).

\section{Superfícies geomórficas}

Utilizando-se os critérios de Ruhe (1969) e Daniels et al. (1971), foram identificadas 5 superfícies geomórficas, que foram representadas em um mapa (Figura 3).

A TABELA 2 mostra as áreas de cada superfície geomórfica e sua porcentagem em relação à área total. A superfície IV é dominante na área.

A superfície I é formada por um platô no divisor de águas da microbacia e está situado aproximadamente nas cotas 615 a $620 \mathrm{~m}$. Essa superfície pode ter se formado por processos erosivos ou deposicionais, mas Bjornberg \& Landim (1966) citam que estas formações superficiais na região de Piracicaba tem origem coluvial. Essa superfície assemelha-se às superfícies descritas por Lepsch (1977), Lobo (1984) e Vidal-Torrado (1994). Provavelmente esteja relacionada com a superfície Rio Claro, caracterizando-se como parte de um antigo pediplano da bacia do Rio Piracicaba (Bigarella et al., 1965; Bjornberg \& Landim, 1966; Penteado, 1976; OkaFiori \& Christofoletti, 1983).

TABELA 1 - Área de ocorrência das formações geológicas e depósitos superficiais e respectiva porcentagem em relação a área total.

\begin{tabular}{lcc}
\hline \multicolumn{1}{c}{$\begin{array}{c}\text { Formações } \\
\text { geológicas } \\
\text { depósitos } \\
\text { superficiais }\end{array}$} & total & relativa \\
\cline { 2 - 3 } & ha & $\%$ \\
\hline Corumbataí & 248,3 & 54,4 \\
\hline Pirambóia & 122,5 & 26,9 \\
Cobertura & 67,9 & 14,9 \\
neo-cenozóica & 16,0 & 3,5 \\
\hline Alúvio-coluvios & 455,7 & 100,0 \\
\hline Total & & \\
\hline
\end{tabular}

TABELA 2 - Área das superfícies geomórficas e sua porcentagem em relação à área total. A superfície Vd corresponde a porção deposicional da superfície V.

\begin{tabular}{lcc}
\hline \multirow{2}{*}{$\begin{array}{c}\text { Superfícies } \\
\text { Geomórficas }\end{array}$} & \multicolumn{2}{c}{ Área } \\
\cline { 2 - 3 } & total & relativa \\
\hline & ha & $\%$ \\
I & 68,6 & 15,0 \\
II & 17,1 & 3,7 \\
III & 99,1 & 21,7 \\
IV & 141,9 & 31,1 \\
Ve & 94,1 & 20,6 \\
Vd & 34,9 & 7,6 \\
\hline Total & 455,7 & 100,0 \\
\hline
\end{tabular}


A superfície II é adjacente à borda da superfície I, constituindo-se como um ombro da encosta. Provavelmente resultou do entalhe provocado pelo ribeirão Marins no pediplano outrora existente sendo portanto de origem erosional. A superfície III, de caráter erosional residual, está localizada predominantemente no divisor de águas dos esporões de vertentes. A superfície IV representa predominantemente as vertentes que se dirigem aos vales dos afluentes do ribeirão Marins. A superfície V, grada diretamente para os canais atuais. Foram separadas sua porção erosional e deposicional $(\mathrm{Vd})$, esta última correspondendo ao fundo dos vales que se apresentam preenchidos por sedimentos de erosão recentes.

Cronologicamente interpretou-se que a superfície I é a mais antiga de todas porque está na cota mais elevada e não grada para nenhuma outra acima dela. $A$ superfície II é mais recente que a I porque a corta. A superfície III é mais recente que a II e a I porque as

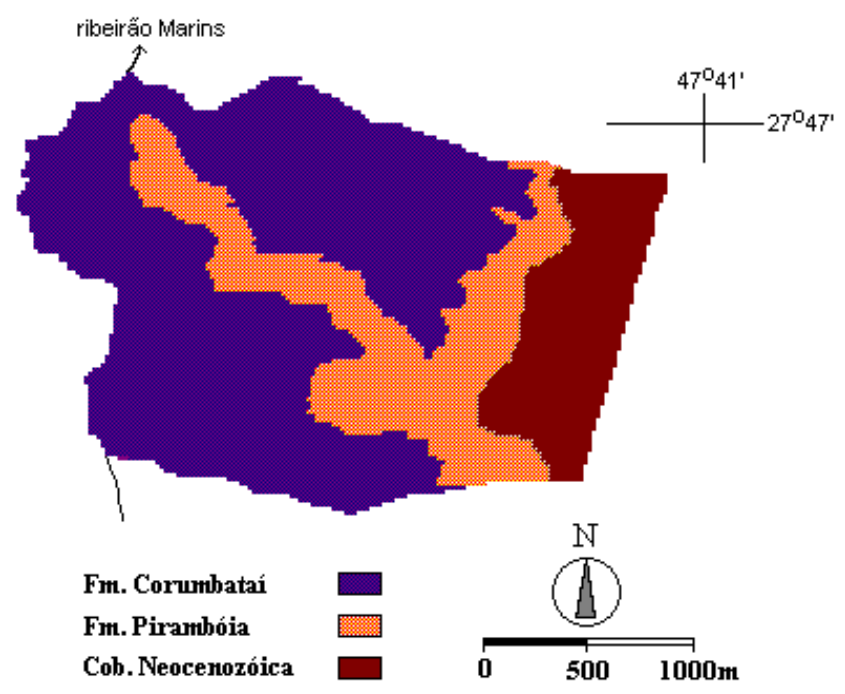

Figura 2 - mapa geológico da área de estudo.

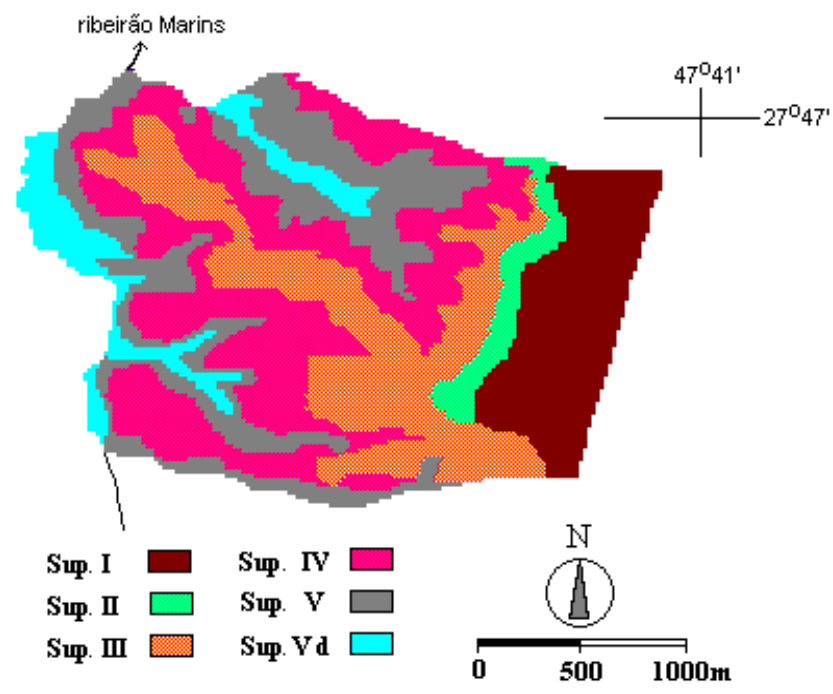

Figura 3 - Mapa de superfícies geomórficas. cortam e é mais velha que a IV porque é seccionada por esta. A superfície $V$ é a mais nova porque grada diretamente para os córregos. A superfície $V$ erosional tem a mesma idade da superfície deposicional para a qual grada. Essa tendência concorda com resultados verificados por Lobo (1984), Cooper et al. (1993) e Vidal-Torrado (1994), que trabalharam na região.

\section{Unidades de mapeamento de solos}

Foi realizado um levantamento onde foram encontradas 5 classes de solos, o LATOSSOLO VERMELHO-AMARELO (LVAdq), ALISSOLO CRÔMICO (AC), ARGISSOLO VERMELHO-AMARELO (PVA), NEOSSOLOS LITÓLICOS (RL) e CAMBISSOLOS HÁPLICOS (Cx). Tais classes desdobram-se em 10 unidades de mapeamento, as quais foram reunidas em mapa (Figura 4). Os dados analíticos das classes estão na TABELA 3.

Pela TABELA 4 nota-se que a área é dominada pelos solos rasos, o que está de acordo tanto com a predominância de siltitos como das superfícies IV e V, mais recentes.

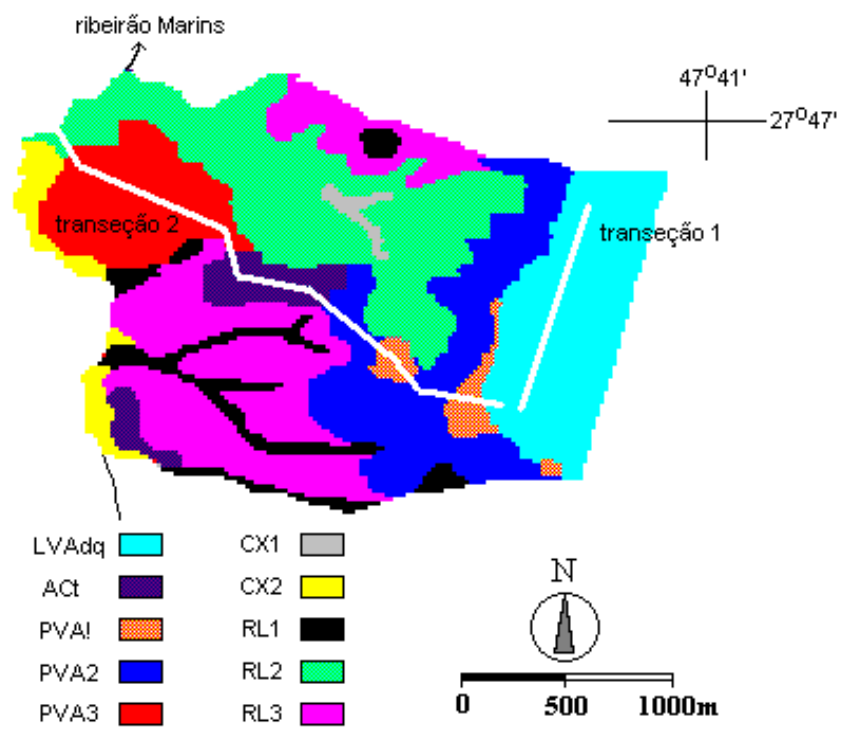

Figura 4 - Mapa pedológico da área estudada correspondendo as unidades: LVAdq: LATOSSOLO VERMELHO-AMARELO Distrófico psamítico, A moderado, textura média; ACt: ALISSOLO CRÔMICO Abrúptico, A moderado, textura média/argilosa; PVA1: ARGISSOLO VERMELHOAMARELO Alumínico, arênico, A moderado, textura arenosa/média; PVA2: ARGISSOLO VERMELHOAMARELO Alumínico, abrúptico, A moderado, textura arenosa/média; PVA3: ARGISSOLO VERMELHO-AMARELO Alumínico, típico, A moderado, textura arenosa/média; CX1: CAMBISSOLO HÁPLICO Eutrófico, Distrófico ou Alumínico, textura média, substrato sedimentos aluvionais; CX2: CAMBISSOLO HÁPLICO Eutrófico, Distrófico ou Alumínico, textura argilosa, substrato sedimentos coluviais; RL1: NEOSSOLO LITÓLICO Distrófico ou Alumínico. A moderado, textura argilosa substrato siltitos da formação Corumbataí; RL2: NEOSSOLO LITÓLICO indiscriminado, substrato siltitos e folhelhos com sílex da formação Corumbataí; RL3: Complexo de RL1 e RL2 + CX1. 
TABELA 3 - Perfis modais e dados analíticos das classes de solos encontradas.

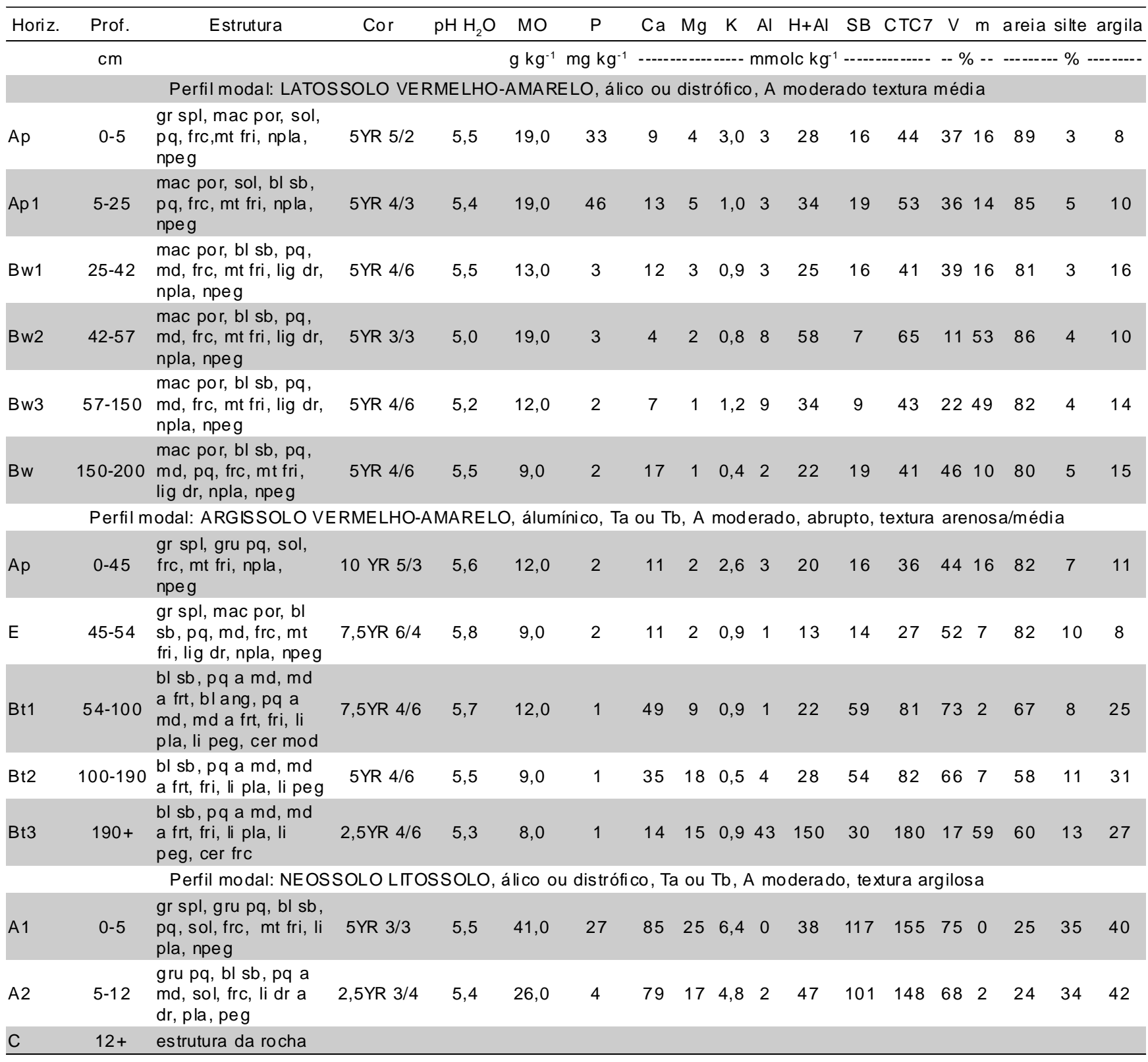

Legenda: (mac por) - maciço poroso; (gr spl) - grãos simples; (gru) - grumos; (bl sb) - blocos subangulares; (bl ang) blocos angulares; (pq) - pequeno; (md) - médio; (frc) - fraco; (sol) - solto; (frt) - forte; (dr) - duro; (lig dr) - ligeiramente duro; (mt fri) - muito friável; (npla) - não plástico; (npeg) - não pegajoso; (li pla) - ligeiramente plástico; (li peg) - ligeiramente pegajoso); (pla) - plástico; (peg) - pegajoso; (cer mod) - cerosidade moderada; (cer frc) - cerosidade fraca;

A unidade LVAdq, situa-se no topo da área e o seu substrato geológico é a cobertura neo-cenozóica. As unidades de mapeamento ACt, PVA1, PVA2 e PVA3 associam-se principalmente às rochas sedimentares da formação Pirambóia. Com excessão da unidade ACt, que possui textura média/argilosa, as demais possuem textura arenosa/média.

\section{Transeções}

A transeção 1 está localizada no topo da área, sobre a cobertura neo-cenozóica. A amplitude topográfica entre o primeiro ponto e o último é de 20 m (Figura 5).

Os gráficos (Figura 6) mostram que apesar de se tratar de uma cobertura homogênea, existe uma diferença de comportamento dos parâmetros analisados a partir da metade da transeção. A relação areia muito fina/fina (AMF/AF) tanto na camada "a" como na "b" indicam uma mudança a partir do ponto 10 , provocada pelo aumento da quantidade de areia muito fina (Figura 6e). Jimenez Rueda \& Demattê (1988) e Vidal-Torrado (1994) utilizaram-se das relações entre frações de areia para inferir sobre diferenças entre materiais de origem. A diferença mostrada na relação AMF/F a partir da metade desta transeção parece ser diferenciada em se tratando de uma cobertura neo-cenozóica bastante antiga e 
intemperizada. Isso pode ser explicado pelo fato de que na segunda metade dessa transeção, essa cobertura está sobre sedimentos argilosos e isso provavelmente influenciou a sua textura e consequentemente seus atributos físicos e químicos. Isso explicaria a diferença detectada pela relação AMF/F que sugere mudança de substrato geológico (figura 5). Do mesmo modo os valores de saturação por bases, saturação por alumínio, argila, cálcio parecem ter dois comportamentos nesta transeção (Figura 6). Tais diferenças também poderiam estar associadas a remanejamentos laterais externos e internos (sobretudo), em consequência dos fluxos hídricos principalmente internos que poderiam estar carreando finos para jusante do transecto.

A transeção 2 situa-se no divisor de águas de uma vertente e estende-se desde o topo até o ribeirão Marins (Figura 7).

Os valores de V\% apresentam grande variação entre os pontos de coleta tanto na camada superficial

TABELA 4 - Área de ocorrência das unidades de mapeamento e respectiva porcentagem em relação à área total.

\begin{tabular}{lcc}
\hline \multirow{2}{*}{$\begin{array}{l}\text { Unidades de } \\
\text { Mapeamento }\end{array}$} & \multicolumn{2}{c}{ Área } \\
\cline { 2 - 3 } & total & relativa \\
\hline LVAdq & ha & $\%$ \\
ACt & 72,9 & 15,9 \\
\hline PVA1 & 18,4 & 4,0 \\
PVA2 & 10,6 & 2,3 \\
\hline PVA3 & 70,3 & 15,4 \\
CX1 & 44,6 & 9,7 \\
CX2 & 14,4 & 3,1 \\
RL1 & 3,7 & 0,8 \\
RL2 & 99,6 & 21,8 \\
RL3 & 26,2 & 5,7 \\
\hline Total & 95,0 & 20,8 \\
\hline
\end{tabular}

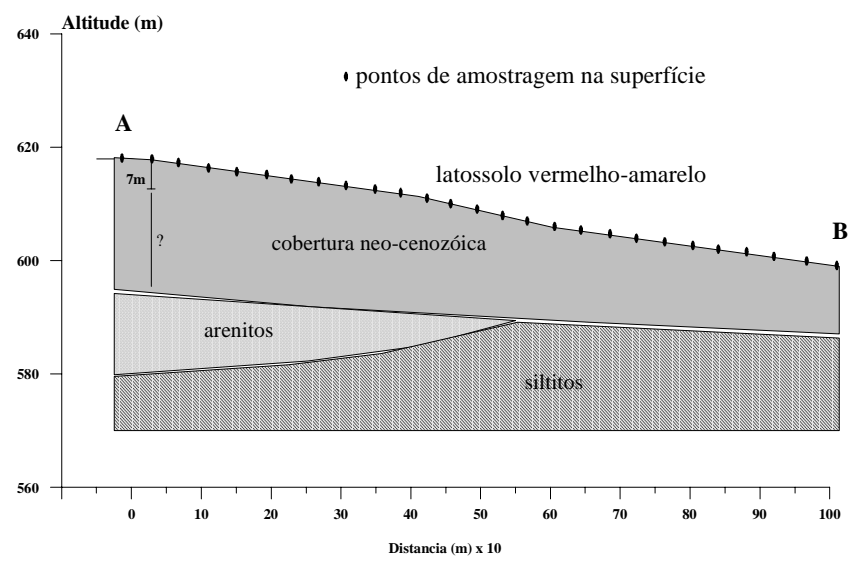

Figura 5 - Perfil topográfico da transeção 1, com a disposição hipotética das camadas. (a) como na subsuperficial (b), mas em geral há uma tendência de incremento de bases trocáveis ao longo da transeção, ou seja, a saturação por bases aumenta da superfície geomórfica mais velha para a mais jovem, ou em relação aos solos a saturação por bases aumenta do solo mais intemperizado para os solos mais imaturos (Figura 8d). Já a saturação por alumínio tem comportamento inverso ao $\mathrm{V} \%$, diminuindo ao longo da vertente, tanto na camada "a" como na "b" (Figura 8b).

O teor de argila, em ambas as camadas, aumenta no sentido do declive, sendo o teor de argila na segunda camada sempre maior (Figura 8a). Isto relaciona-se com a estratigrafia da área, onde o substrato mais argiloso está nas cotas inferiores.

A relação silte/argila apresenta valores mais baixos na transeção 1 (Figuras $6 \mathrm{c}$ e $8 \mathrm{c}$ ) do que na 2, indicando que, no topo da área estudada, os solos são mais intemperizados.

Os teores de argila e cálcio (Figuras 8a e 8f) apresentam valores relativamente mais elevados na região mediana da transeção, possivelmente o $\mathrm{Ca}$ sofreu influência do manejo da cultura da cana. Nesta região o comportamento da relação AMF/F sugere mudança de substrato geológico.

\section{Relações solo - substrato geológico - super- fícies geomórficas}

As interações entre os solos, a geologia e a geomorfologia foram estabelecidas através do cruzamento dos mapas temáticos.

Foram utilizados dois tipos de índices: o pedológico e o litológico. O pedológico permite comparar a homogeneidade das superfícies geomórficas e das formações geológicas quanto aos tipos de solos. O índice litológico avalia a homogeneidade das superfícies em termos de material geológico.

Segundo Murray (1985), números índices podem ser utilizados para mostrar as variações geográficas de uma variável, ou de um grupo delas, correlacionadas no tempo, à localização geográfica e a muitas outras características.

Dessa forma, a superfície geomórfica I está totalmente sobre a cobertura neo-cenozóica, as superfícies II e III estão predominantemente assentadas sobre os arenitos da formação Pirambóia, enquanto as superfícies IV, V e Vd, estão sobre os siltitos da formação Corumbataí e em menor escala sobre alúvios-colúvios (TABELA 5).

A geologia da área forneceu subsídios para explicar de forma adequada o relevo local. A superfície I está sobre o manto espesso e poroso, com boa infiltração de água e alta resistência à erosão, por isso o relevo é quase plano e a superfície é a mais antiga. Os arenitos são mais permeáveis e friáveis que os siltitos, portanto mais facilmente intemperizáveis. Esse material, de esculturação relativamente fácil, conferiu às superfícies II e III formas mais suaves. As superfícies IV 


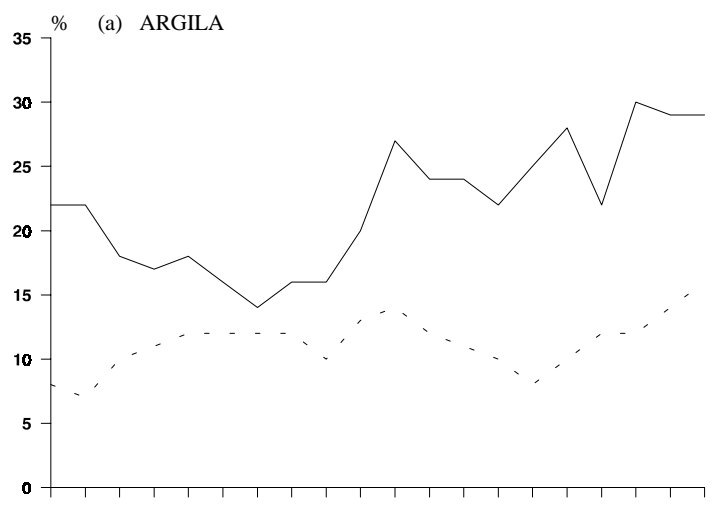

(c) RELAÇÃO SILTE/ARGILA

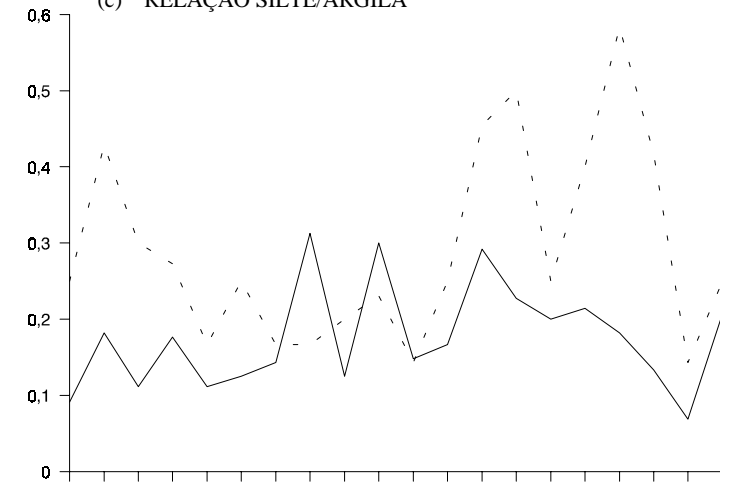

(e) AREIA MUITO FINA/FINA

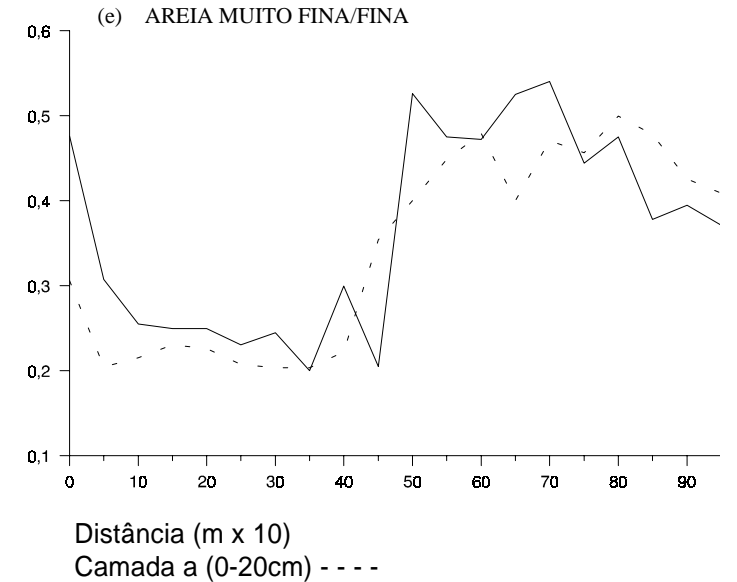

(b) SATURAÇÃO POR ALUMINIO
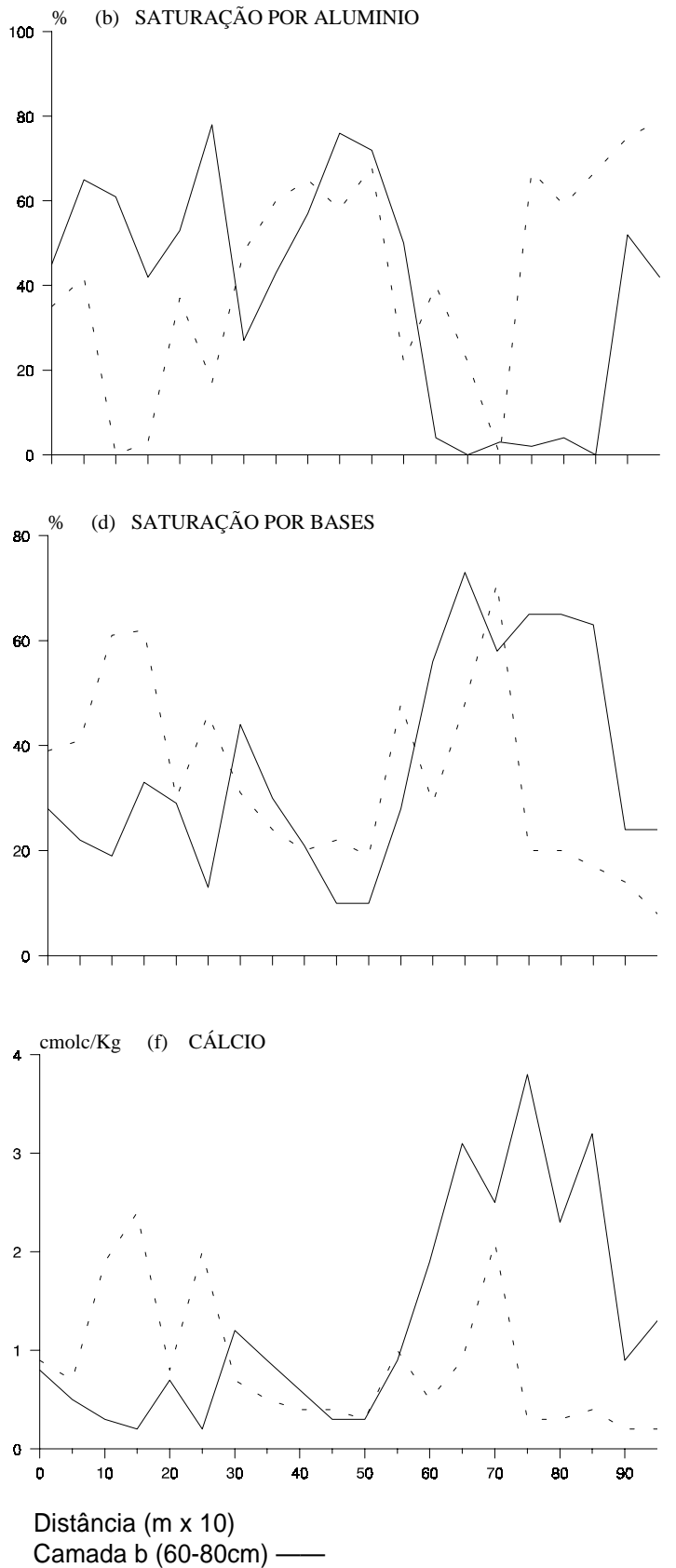

Figura 6 - Gráficos de atributos químicos e físicos de amostras, em duas camadas a e b, da transeção 1; (a) teor de argila; (b) saturação por alumínio; (c) relação silte/argila; (d) saturação por bases; (e) relação areia muito fina/fina; (f) cálcio

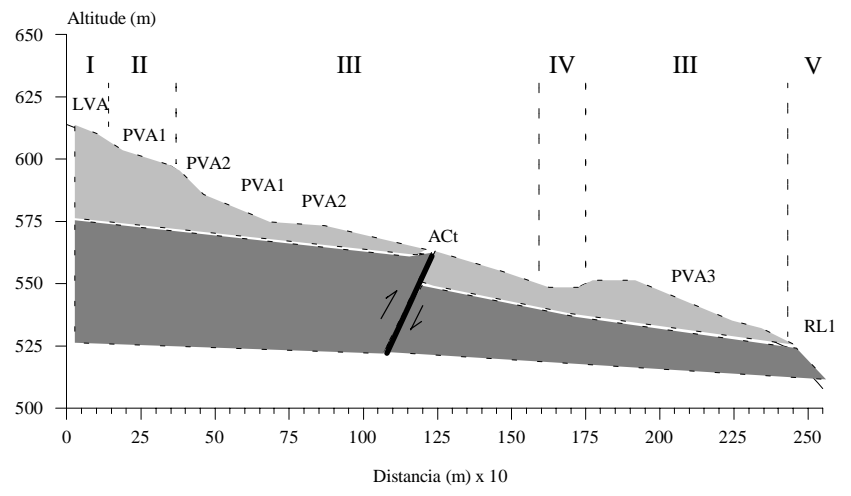

Figura 7 - Perfil topográfico da transeção 2. e Ve possuem as maiores declividades da área, justamente porque os siltitos e folhelhos, quase impermeáveis, proporcionam maior escorrimento superficial e consequentemente maior erosão, causando intenso ravinamento, que se aprofunda formando escarpas e encostas declivosas, características dessas superfícies.

A seqüência temporal das superfícies geomórficas não apresenta correlação com a seqüência cronológica da coluna estratigráfica. A superfície I, mais velha, corresponde a cobertura neo-cenozóica que, como já foi visto, é posterior às formações Pirambóia e Corumbataí, portanto é inversa à geomeorfologia. 


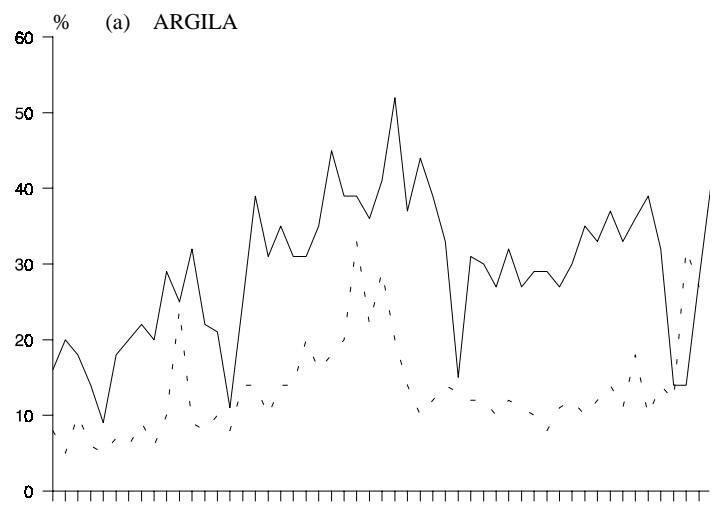

(c) RELAÇÃO SILTE/ARGILA

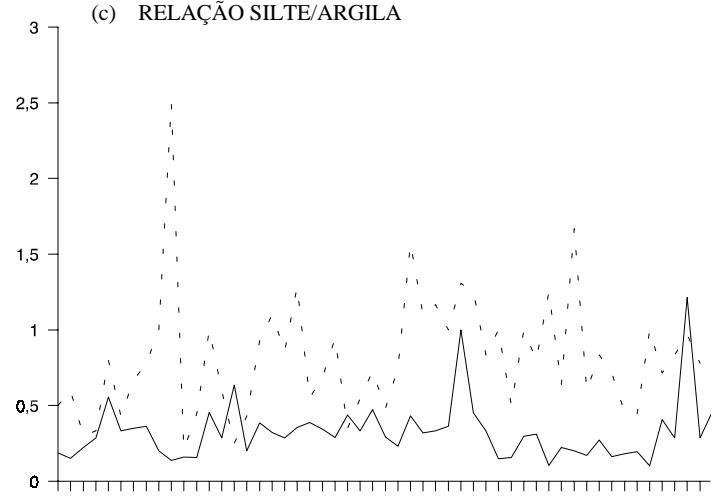

(e) RELAÇÃO AREIA MUITO/FINA

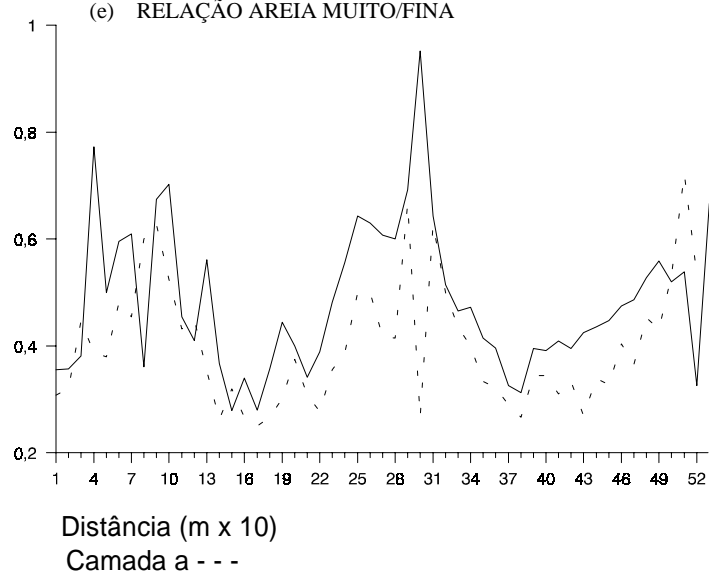

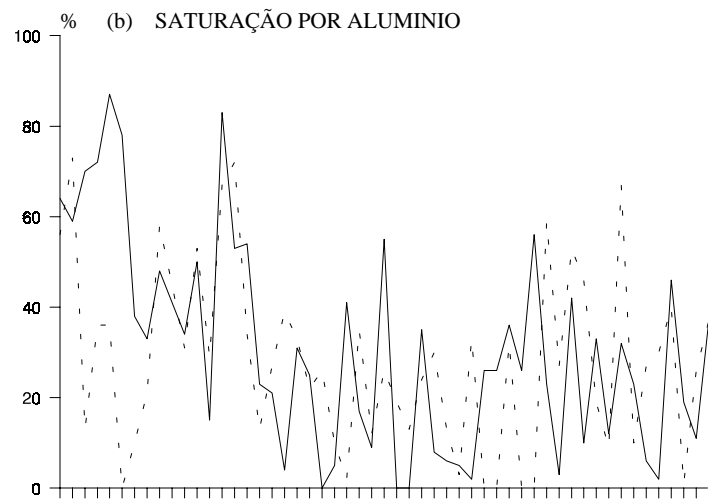
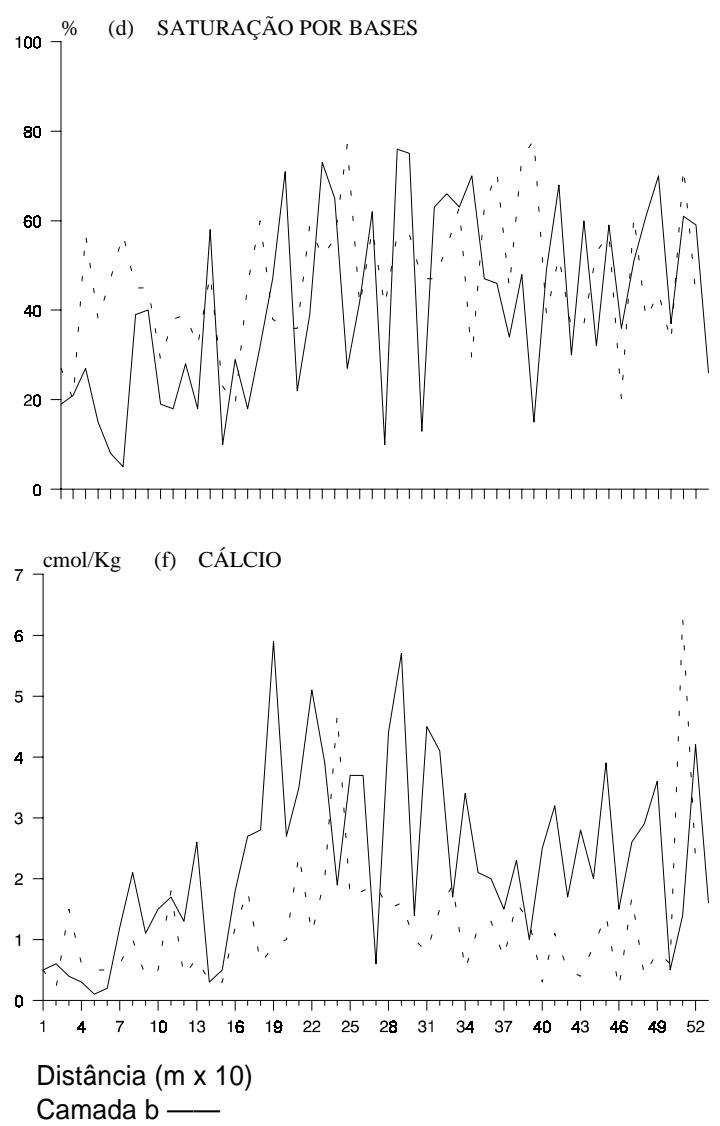

Figura 8 - Gráficos dos atributos químicos e físicos da transeção 2, em duas camadas: (a) teor de argila; (b) saturação por alumínio; (c) relação silte/argila; (d) saturação por bases; (e) relação areia muito fina/fina; (f) cálcio.

TABELA 5 - Porcentagem de ocorrência e índices de homogeneidade litológico dos substratos geológicosde cordo com as respectivas superfícies geomórficas porcentagem em relação à área da superfícies).

\begin{tabular}{|c|c|c|c|c|c|}
\hline \multirow[b]{2}{*}{$\begin{array}{l}\text { Superfície } \\
\text { Geomórfica }\end{array}$} & \multicolumn{4}{|c|}{ Substrato geológico } & \multirow[b]{2}{*}{ I.H. litológico } \\
\hline & $\begin{array}{l}\text { Alúvio/ } \\
\text { colúvio }\end{array}$ & $\begin{array}{c}\text { Cobertura } \\
\text { neo-cenozóica }\end{array}$ & $\begin{array}{l}\text { Formação } \\
\text { Pirambóia }\end{array}$ & $\begin{array}{c}\text { Formação } \\
\text { Corumbataí }\end{array}$ & \\
\hline & 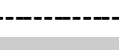 & -------------- & $\%$ & ---------- & 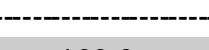 \\
\hline I & & 100,0 & & & 100,0 \\
\hline II & & & 100,0 & & 100,0 \\
\hline III & & & 92,7 & 7,2 & 86,4 \\
\hline IV & & & 8,6 & 91,3 & 84,1 \\
\hline Ve & 17,0 & & 1,2 & 81,8 & 70,0 \\
\hline $\mathrm{Vd}$ & 4,0 & & & 96,3 & 93,0 \\
\hline
\end{tabular}


A superfície $V$ deposicional, mais jovem, corresponde ao material geológico mais recente, ou seja, aos alúvios-colúvios. O material geológico mais antigo, a formação Corumbataí, corresponde em grande parte à superfície IV.

O substrato geológico mais homogêneo em termos de ocorrência de solos, representado pelas unidades de mapeamento, é a cobertura neo-cenozóica, uma vez que nela ocorre principalmente o LATOSSOLO VERMELHO-AMARELO, o que de certa forma é freqüente, tendo-se em vista os resultados dos trabalhos de Lepsch, 1977; Coelho et al., 1994 e Vidal-Torrado, 1994, dentre outros. O arenito da formação Pirambóia mostrou predomínio de ocorrência de unidades de mapeamento a classe dos ARGISSOLOS VERMELHOAMARELOS, os quais perfazem, em conjunto, $85 \%$ do total da área ocupada por esse substrato geológico, com grande participação da unidade PVA2. $\mathrm{Na}$ área que compreende os siltitos da formação Corumbataí ocorrem basicamente solos pouco desenvolvidos, freqüentemente pouco profundos, como os NEOSSOLOS LITÓLICOS E CAMBISSOLOS HÁPLICOS, mas ocorrem também áreas de ARGISSOLOS. Essa formação mostrou a maior diversidade de ocorrência de solos (TABELA 6). Nos alúvios-colúvios foram encontrados apenas NEOSSOLOS LITÓLICOS e CAMBISSOLOS HÁPLICOS, e isso fez com que o $1 \%$ pedológico dos mesmos fosse maior que 0 da formação Corumbataí, apesar da grande heterogeneidade característica desses materiais coluviais.

A relação entre substrato geológico e unidades de solos é bastante clara. A homogeneidade do substrato geológico, aliada ao relevo, condicionam a diversidade de solos que são encontrados. Dessa forma, utilizando a relação superfícies geomórficas-substrato geológico entende-se porque a maior parte dos solos da superfície são de textura média, os solos das superfícies II e III são arenosos e os solos das superfícies IV e Ve são argilosos.

A relação entre solos e superfícies geomórficas é representada pela tendência de que quanto mais velha e estável é a superfície, mais homogênea ela deve ser em relação aos solo que nela ocorrem, ou seja, a complexidade e variabilidade de solos é inversamente proporcional à idade da superfície. A variação dos tipos de solos, assim como a estabilidade geomórfica das superfícies, está estreitamente ligada ao tempo e ao relevo, como há muito tempo foi interpretado pela extinta Comissão de Solos (Brasil, 1960), entre outros. As superfícies geomorficamente mais estáveis oferecem condições para um maior desenvolvimento e estabilidade dos solos, é o caso da superfície I. Superfícies menos estáveis possuem normalmente solos menos desenvolvidos e mais variados. Vários autores também observaram esta tendência (Lepsch, 1977; Uberti \& Klamt, 1984; Vidal-Torrado, 1994; Coelho et al., 1994).

Os solos presentes nas diferentes superfícies estão em correlação com o tipo de substrato rochoso (TABELAS 6 e 7), ou seja, relações entre solos e superfícies geomórficas são também uma consequência das variações litológicas, uma vez que o substrato geológico é o principal fator determinante do relevo da distribuição dos solos nas superfícies.

TABELA 6 - Porcentagem de ocorrência e índice de homogeneidade pedológico dos solos de acordo com os respectivos substratos geológicos (porcentagem em relação à área do substrato geológico).

\begin{tabular}{|c|c|c|c|c|c|c|c|c|c|c|c|}
\hline \multirow{2}{*}{$\begin{array}{l}\text { Substrato } \\
\text { Geológico }\end{array}$} & \multicolumn{10}{|c|}{ Solos } & \multirow{2}{*}{$\begin{array}{l}\text { I.H. } \\
\text { pedológico }\end{array}$} \\
\hline & LVAdq & $\mathrm{ACt}$ & PVA1 & PVA2 & PVA3 & CX1 & CX2 & RL1 & RL2 & RL3 & \\
\hline & --------- & ---- & ---- & - & ------ & ------ & b--- & ----- & ------ & ------ & ------------- \\
\hline Aluvios-Coluvios & & & & & & 3,4 & 17,8 & 43,8 & 25,6 & 10,0 & 30,2 \\
\hline Cob. ceno zóica & 96,3 & & 1,9 & 1,8 & & & & & & & 92,8 \\
\hline Fm. Pirambóia & 5,6 & 8,2 & 7,6 & 57,3 & 12,6 & & & 6,6 & 0,8 & 1,3 & 36,4 \\
\hline Fm. Corumbataí & & 3,4 & & & 11,8 & 5,5 & 0,8 & 33,8 & 8,6 & 36,9 & 27,6 \\
\hline
\end{tabular}

TABELA 7 - Porcentagem de ocorrência e indice de homogeneidade pedológico dos solos de acordo com as respectivas superfícies geomórficas (porcentagem em relação à área das superfícies).

\begin{tabular}{|c|c|c|c|c|c|c|c|c|c|c|c|}
\hline \multirow{2}{*}{$\begin{array}{l}\text { Superfície } \\
\text { Geomórfica }\end{array}$} & \multicolumn{10}{|c|}{ Solos } & \multirow{2}{*}{$\begin{array}{c}\text { I.H. } \\
\text { pedológicc }\end{array}$} \\
\hline & LVAdq & ACt & PVA1 & PVA2 & PVA3 & CX1 & $\mathrm{CX} 2$ & RL1 & RL2 & RL3 & \\
\hline & \multicolumn{11}{|c|}{ 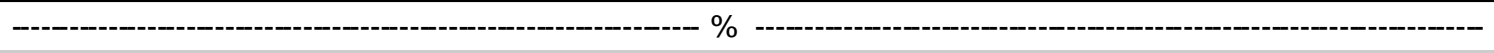 } \\
\hline I & 93,9 & & 1,8 & 1,7 & & & & & & & 88,2 \\
\hline II & 31,9 & & 22,6 & 43,1 & & & & & & & 33,9 \\
\hline III & 1,2 & 9,9 & 5,3 & 49,3 & 16,7 & & & 9,1 & 1,3 & 4,2 & 29,4 \\
\hline IV & & 5,0 & & 7,5 & 9,4 & 0,1 & & 29,4 & 4,7 & 41,3 & 27,6 \\
\hline $\mathrm{Ve}$ & & 1,2 & & & 7,5 & 3,4 & 5,4 & 40,2 & 12,9 & 29,2 & 27,3 \\
\hline $\mathrm{Vd}$ & & & & & 18,4 & 30,3 & 5,0 & 22,9 & 5,1 & 5,9 & 15,3 \\
\hline
\end{tabular}

Scientia Agricola, v.58, n.2, p.361-371, abr./jun. 2001 
O LATOSSOLO VERMELHO-AMARELO textura média está relacionado à cobertura neocenozóica e à superfície I, onde o relevo é plano. Os ARGISSOLOS VERMELHO-AMARELOS abruptos de textura predominantemente arenosa/média relacionam-se ao arenito da formação Pirambóia, às superfícies II e III em declives suaves. Os solos NEOSSOLOS LITÓLICOS argilosos estão associados aos siltitos e sílex da formação Corumbataí e às superfícies IV e Ve em áreas escarpadas com declive acentuado. Os CAMBISSOLOS HÁPLICOS de textura variada relacionam-se aos alúvios-colúvios presentes na superfície $\mathrm{V}$ deposicional em locais de declive plano a suave ondulado, no fundo dos vales e nas margens do ribeirão.

Dessa forma as variações dos atributos químicos e físicos que ocorrem entre as superfícies são, em primeira instância, principalmente decorrentes das litologias da área, isto é, litodependentes. Já as diferenças morfológicas dos solos encontrados podem ser atribuidas principalmente ao fator relevo dentro de cada superfície. Superfícies em que o relevo é declivoso ou que apresentam variações topográficas não tão acentuadas porem frequentes, terão maiores variações morfológicas nos solos. É o caso das superfícies IV e V, o que pode estar relacionado aos fluxos hídricos tanto superficiais como subsuperficiais do pedoclima. Assim, tanto as características químicas como físicas analisadas sugerem uma tendência congruente em relação à posição que as superfícies ocupam na paisagem, ao material geológico predominante nas superfícies e ao tempo de formação do solo, como indicaram vários autores desde a década de 60 .

Os atributos dos solos apresentam menor variabilidade nas superfícies I e II, mais antigas e estáveis, e maior nas superfícies IV e V, mais jovens e menos estáveis. Superfícies mais antigas e geomorfologicamente mais estáveis tendem a ter menor variabilidade dos atributos químicos e físicos dos solos, ao contrário, as superfícies mais jovens possuem maior variabilidade. O que está de acordo com Lepsch, (1977) e Uberti \& Klamt, (1984), entre outros. Por outro lado, os materiais que recobrem as mais antigas já teriam se depositado mais intemperizados, o que favoreceria a pedogênese e, pelo fato de se encontrarem nos topos apresentam tendência a uma drenagem vertical e homogeneizante, portanto latossólica.

\section{CONCLUSÕES}

A variabilidade dos atributos químicos e físicos dos solos na camada de $60-80 \mathrm{~cm}$ é influenciada principalmente pela natureza química e física do substrato geológico, enquanto que os atributos morfológicos são determinados principalmente pelo relevo.

As relações estabelecidas na área estudada podem ser extrapoladas para outras vizinhas, contribuindo dessa forma para futuros levantamentos de solos que possam vir a ser realizados nessa microbacia e em outras vizinhas.

\section{AGRADECIMENTOS}

À FAPESP e ao CNPq pelo auxílio financeiro para realização deste trabalho.

Aos professores Gerd Sparovek e Quirijn de Jong van Lier, ambos da ESALQ, pelas sugestões oferecidas durante o desenvolvimento deste trabalho

\section{REFERÊNCIAS BIBLIOGRÁFICAS}

AZOLIN, M.A.D.; KLAMT, E.; SANTOS, M.C.C. dos. Relações solo-superfícies geomórficas e material de origem a oeste da depressão central e campanha no Rio Grande do Sul. In: CONGRESSO BRASILEIRO DE CIÊNCIA DO SOLO, 15., Campinas, 1975. Anais. Campinas: SBCS, 1976. p.345-350.

BERG, M. van den; LEPSCH, I. F.; SAKAI, E. Solos de planícies aluviais do vale do Ribeira do Iguape: I Padrões de distribuição. Revista Brasileira de Ciência do Solo, v.11, p.305-313, 1987.

BIGARELLA, J.J.; MOUSINHO, M.R.; SILVA, J.X. Pediplanos, pedimentos e seus depósitos correlativos no Brasil. Boletim Paranaense de Geografia, v.16/17, p.117-151, 1965.

BJORNBERG, A.J.S.; LANDIM, P.M.B. Contribuição ao estudo da formação Rio Claro, neocenozóico. Boletim da Sociedade Brasileira de Geologia, v.15, p.43-68, 1966.

BRASIL Ministério da Agricultura Comissão de Solos. Levantamento de reconhecimento de solos do Estado de São Paulo. Rio de Janeiro: Ministério da Agricultura, CNEPA, 1960. 634p. (Boletim, 12).

CAMARGO, O.A. de; MONIZ, A.C.; JORGE, J.A.; VALADARES, J.M.A.S. Métodos de análise química, mineralógica e física de solos do IAC. Campinas: Instituto Agronômico, 1986. 49p.

COELHO, R.M.; LEPSCH, I.F. ; MENK, J.R.F. Relações solorelevo em uma encosta com transição arenito-basalto em Jaú (SP). Revista Brasileira de Ciência do Solo, v.18, p.125137, 1994.

COOPER, M.; LEPSCH, I. F.; VIDAL-TORRADO, P. Caracterização dos solos ao longo dos compartimentosde uma vertentesobre diabásio em Piracicaba (SP). In: CONGRESSO BRASILEIRO DE CIÊNCIA DO SOLO, 24., Campinas, 1993. Anais. Campinas: SBSC, 1993. p.330-333.

DANIELS, R.B.; GAMBLE, E.F. ; CADY, J.G. The relation between geomorphology and soil morphology and genesis. Advances in Agronomy, v.23, p.51-87, 1971.

JIMENEZ RUEDA, J.R.; DEMATTÊ, J.L.I. Solos originados de lamitos da formação Marilia (grupo Bauru) da região de Monte Alto, SP. Revista Brasileira de Ciência do Solo, v.12, p.161$170,1988$.

INSTITUTO DE PESQUISAS TECNOLÓGICAS. Mapa geológico do Estado de São Paulo. Escala 1:500.000. Divisão de Minas e Geologia Aplicada do Instituto de Pesquisas Tecnológicas do Estado de São Paulo. São Paulo: IPT, 1981a.

INSTITUTO DE PESQUISAS TECNOLÓGICAS. Mapa geomorfológico do Estado de São Paulo. Escala 1:1.000.000. Divisão de Minas e Geologia Aplicada do Instituto de Pesquisas Tecnológicas do Estado de São Paulo. São Paulo: IPT, 1981b. 
LEPSCH, I.F. Superfícies geomorfológicas e depósitos superficiais neocenozóicos em Echaporã, SP. Boletim Paulista de Geografia, v.53, p. 5-34, 1977.

LOBO, A.E.M. Relações solo-superfícies fisiográficas em uma transeção de Piracicaba, SP, Piracicaba, 1984. 164p. Tese (Doutorado) - Escola Superior de Agricultura "Luiz de Queiroz", Universidade de São Paulo.

MURRAY, R.S. Estatística. São Paulo: Shaum McGraw-Hill, 1985. 453p.

OKA-FIORI, C.; CRISTOFOLETTI, A. Mapeamento das formações superficiais da região de São Pedro-Piracicaba (SP, Brasil). Geociências, v.2, p.59-64, 1983.

OLIVEIRA, J.B. de; ALFONSI, R.R. ; PEDRO JR., M.J. Regimes hídricos e térmicos dos solos do Estado de São Paulo. In: CONGRESSO BRASILEIRO DE CIÊNCIA DO SOLO, 15. Campinas, 1970. Anais. Campinas: SBCS, 1976. p.359-362.

OLIVEIRA, J.B.; PRADO, H. Carta pedológica Semi-detalhada do Estado de São Paulo. Folha de Piracicaba, (escala 1:100.000). Campinas: Instituto Agronômico; Instituto Geográfico e Cartográfico, 1989.

PENTEADO, M.N. Geomorfologia do setor centro ocidental da depressão periférica paulista. São Paulo: USP, Instituto de Geografia. 1976. 86p. (Série Teses e Monografias, 22)

PEREZ FILHO, A.; DONZELLI, J.B.; LEPSCH, I.F. Relações solo geomorfologia em várzea do Rio Mogi-Guacu (SP). Revista Brasileira de Ciência do Solo, v.4, p.181-187, 1980.
RAIJ, B. van; QUAGGIO, J.A.; CANTARELLA, H.; FERREIRA, M.E.; LOPES, A.S.; BATAGLIA, O.A. Análise química do solos pra fins de fertilidade. Campinas: Fundação Cargill, 1987. 165p.

RODRIGUES, T.E.; KLANT, E. Mineralogia e gênese de uma sequencia de solos do Distrito Federal. Revista Brasileira de Ciência do Solo, v.2, p.132-139, 1978.

RUHE, R.V. Quaternary landscape in lowa. Ames: lowa State University Press, 1969. 255p.

SPAROVEK, G.; De JONG Van LIER, Q.; LEPSCH, I.F. GMAP: Um programa de manipulação de mapas temáticos adaptados a computadores de pequeno porte. O exemplo do município de Piracicaba. Boletim Informativo da Sociedade Brasileira de Ciência do Solo, v.18, p.15-19, 1993.

UBERTI, A.A.; KLAMT, E. Relações solo-superfícies geomórficas na encosta inferior do nordeste do Rio Grande do Sul. Revista Brasileira de Ciência do Solo, v.8, p.124132, 1984

VIDAL TORRADO, P. Morfogênese e pedogênese no distrito de Tupi (Piracicaba-SP). Piracicaba, 1994. 208p. Tese (Doutorado) - Escola Superior de Agricultura "Luiz de Queiroz", Universidade de São Paulo.

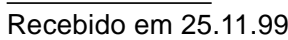

